\title{
COMUNICAÇÃO
}

\section{DESEMPENHO DE GENÓTIPOS DE SOJA-HORTALIÇA DE CICLO PRECOCE [Glycine max (L.) MERRIL] EM DIFERENTES DENSIDADES}

\author{
Performance of genotypes of early-cycle vegetable soybeans [Glycine max (L.) Merril] in \\ different densities
}

\author{
Hamilton César de O. Charloํㅜ, Renata Castoldi' ${ }^{1}$ Pablo Forlan Vargas', \\ Leila Trevizan Braz ${ }^{2}$, José Lindorico de Mendonça ${ }^{3}$
}

\begin{abstract}
RESUMO
Objetivando-se avaliar o desempenho de dois genótipos de soja-hortaliça de ciclo precoce [Glycine max (L.) Merril], em diferentes densidades, foi instalado um ensaio, em área experimental do Setor de Olericultura e Plantas Aromático-Medicinais, pertencente ao Departamento de Produção Vegetal, nas dependências da Faculdade de Ciências Agrárias e Veterinárias (FCAVUNESP), Campus de Jaboticabal-SP. O delineamento experimental foi o de parcelas subdivididas, adotando-se nas parcelas os genótipos e nas subparcelas as densidades, com quatro repetições por tratamento. Cada parcela experimental foi constituída por quatro linhas de 4,5m de plantio, com densidades de 20,10 e 7 plantas por metro e $0,60 \mathrm{~m}$ nas entrelinhas, sendo consideradas para avaliação 20 plantas por parcela, das duas linhas centrais. As sementes foram semeadas em bandejas de poliestireno expandido de 128 células, contendo substrato Plantmax Hortaliças ${ }^{\circledR}$. O transplantio ocorreu dez dias após a semeadura, em solo devidamente preparado, conforme recomendações para a cultura. A colheita foi realizada quando os legumes estavam em estádio reprodutivo R6. Avaliaramse os genótipos JLM010 e CNPSOI quanto às características: número médio de legumes por planta, número médio de sementes por legume, massa fresca de 100 sementes e produtividade estimada de grãos imaturos. Com base nos resultados obtidos concluiu-se que o genótipo JLM010 é o mais recomendado e deve ser plantado na densidade de 7 plantas por metro.
\end{abstract}

Termos para indexação: Glycine max, produtividade, densidades.

\begin{abstract}
With the aim of evaluating the performance of two genotypes of early-cycle soybeans [Glycine max (L.) Merril] in different spacings, a study was carried out in the experimental area of the Sector of Vegetable Crops and Aromatic Medicinal Plants, belonging to the Department of Crop Sciences, College of Agricultural and Veterinary Sciences (FCAV-UNESP), Jaboticabal Campus-SP. The experimental design used was the one of subdivided parcels, each parcel representing the genotypes and the subparcels being the densities, where four replications were used for each treatment. Plots comprised four rows measuring with populations of 20, 10 and 7 plants by meter, and $0.60 \mathrm{~m}$ between rows, where each parcel consisted of 20 plants. Seeds were sowed in expanded polystyrene trays with 128 pyramidal cells, contend substratum Plantmax Hortaliças®. Transplanting was performed ten days after sowing, to a soil previously fertilized as recommended to the crop. Harvesting was performed when pods reached the reproductive stage R6. The following genotypes were used: JLM010 and CNPSOI. The mean earliness, mean number of pods per plant, mean number of seeds per pod, fresh weight of 100 seeds and estimated yield of immature grains were measured. Results showed that the genotype JLM010 is the best for vegetable soybean production, because a higher fresh weight of 100 seeds was obtained with a population of 7 plants by meter.
\end{abstract}

Index terms: Glycine max, yield, densities.

(Recebido em 10 de janeiro de 2007 e aprovado em 12 de junho de 2007)

Recentemente introduzida no Brasil, a soja-hortaliça (edaname) [Glycine $\max ($ L.) Merril] vem despertando grande interesse na população. Atualmente, a soja-hortaliça é consumida no Japão, China, Coréia, Tailândia, Indonésia, Malásia, Filipinas, Cingapura, Nepal, Sri Lanka, Estados
Unidos e Austrália (MENDONÇA \& CARRÃO-PANIZZI, 2003).

A soja-hortaliça é uma das hortaliças com maior potencial de crescimento de mercado no Brasil, pois ela pode ser uma alternativa natural na reposição hormonal,

\footnotetext{
Mestres - Departamento de Produção Vegetal - Faculdade de Ciências Agrárias e Veterinárias/FCAV - Universidade Estadual Paulista/UNESP - Via de Acesso Professor Paulo Donato Castellane, s/n - 14884-900 - Jaboticabal, SP - hamiltoncharlo@gmail.com; rcastoldi@gmail.com; pfvargas@gmail.com ${ }^{2}$ Doutora - Departamento de Produção Vegetal - Faculdade de Ciências Agrárias e Veterinárias/FCAV - Universidade Estadual Paulista/UNESP - Via de Acesso Professor Paulo Donato Castellane, s/n - 14884-900 - Jaboticabal, SP - leilatb@fcav.unesp.br

${ }^{3}$ Mestre - Transferência de Tecnologia - EMBRAPA Hortaliças/CNPH - Rodovia Brasília/Anápolis, Br 060, Km 09 - Gama - Cx. P. 218 - $70359-970$ Brasilia, DF - mendonça@cnph.embrapa.br
} 
bem como um alimento de grande importância na alimentação humana, especialmente na feminina.

As cultivares de soja-hortaliça devem apresentar características especiais, diferentes da soja comum, como: sementes graúdas com alto teor de proteína, coloração clara do hilo e que conferem boa qualidade organoléptica aos produtos de soja (QO); ausência de enzimas lipoxigenases (AL), conferindo sabor mais suave aos produtos; teor reduzido do inibidor de tripsina Kunitz (KI), o que permite a redução de tratamento térmico e dos custos de processamento e tamanho, coloração e textura de sementes ideais para produção de "natto" ( $\mathrm{PN}$ - alimento fermentado japonês). Entre as cultivares desenvolvidas para esse fim e que apresentam algumas das características citadas, destacam-se: BR 36 (QO); BRS 155 (KR); BRS 213 (AL); BRS 216 (PN); IAC PL-1 (QO); UFVTN 101 (AL); UFVTN 102 (AL); UFVTN 103 (AL); UFVTN 104 (AL); UFVTN 105 (AL), e UFVTNK 106 (AL, KR) (EMBRAPA, 2003).

Os grãos de cultivares de soja-hortaliça são maiores do que os da soja comum e são considerados melhores em sabor, textura e tempo de cozimento. $\mathrm{O}$ ácido fítico, neles encontrado, em níveis mais altos do que nos da soja comum, explica por que são mais tenros e de mais rápida cocção (KONOVSKY \& LUMPKIN, 1990).

Existem muitos genótipos de soja comercial com potencial de uso como soja-hortaliça, porém apresentam produtividades muito variadas, dependendo das condições em que são cultivadas, como solo, clima, época de plantio e densidade.

Em razão da falta de estudos em soja-hortaliça, aliada à grande importância das substâncias presentes na mesma, objetivou-se, no presente trabalho avaliar a influência de densidades de plantio, nas características agronômicas de dois genótipos de ciclo precoce de soja-hortaliça, em Jaboticabal-SP.

O experimento foi conduzido em campo, no período de 15 de setembro de 2005 a 15 de dezembro de 2005, em área experimental do Setor de Olericultura e Plantas AromáticoMedicinais, pertencente ao Departamento de Produção Vegetal, nas dependências da Faculdade de Ciências Agrárias e Veterinárias (FCAV-UNESP), Câmpus de Jaboticabal-SP, cujas coordenadas geográficas são $21^{\circ} 14$ ' 05 "'Latitude Sul, $48^{\circ} 17^{\prime}$ '09' Longitude Oeste e altitude de $614 \mathrm{~m}$.

O clima, segundo a classificação de Köppen, é do tipo Aw com transição para Cwa $\left(\mathrm{VOLPE}^{4}\right)$, e o solo da área experimental foi classificado como sendo Latossolo eutroférrico (EMBRAPA, 1999).

O delineamento experimental foi o de parcelas subdivididas, adotando-se nas parcelas os genótipos e nas subparcelas as densidades. Foram realizadas quatro repetições por tratamento. Cada parcela experimental foi constituída por quatro linhas de plantio, de $4,5 \mathrm{~m}$ de comprimento, com densidades de 20, 10 e 7 plantas por metro e 0,60 $\mathrm{m}$ nas entrelinhas, sendo consideradas para avaliação 20 plantas por parcela, das duas linhas centrais.

Foram avaliados os genótipos JLM010 - porte médio; massa fresca de 100 sementes $=41$ gramas; flor de coloração branca; hilo e grão claros, e originário da AVRDC - Taiwan e CNPSOI - porte médio; massa fresca de 100 sementes $=27,8$ gramas; hilo claro e originário da EMBRAPA - Soja.

Em razão do intenso ataque de pombos em plantios anteriores com semeadura direta, optou-se pela formação das mudas, utilizando-se bandejas de poliestireno expandido, com capacidade para 128 células, acrescido de substrato comercial Plantmax Hortaliças ${ }^{\circledR}$, colocando-se uma semente por célula. As sementes foram previamente inoculadas na proporção de 500 gramas de inoculante, que contém Bradyrhizobium spp. para cada $50 \mathrm{~kg}$ de sementes.

As mudas foram transplantadas aos 10 dias após a semeadura em solo anteriormente preparado e adubado conforme os resultados da análise do solo e recomendação de Raij et al. (1996). Para tanto, foram aplicados em adubação de plantio $40 \mathrm{~kg} \mathrm{ha}^{-1}$ de $\mathrm{P}_{2} \mathrm{O}_{5}$, utilizando como fonte superfosfato simples, e $60 \mathrm{~kg}^{2} \mathrm{ha}^{-1}$ de $\mathrm{K}_{2} \mathrm{O}$, utilizando cloreto de potássio como fonte, o qual foi dividido, aplicando-se metade da dose na adubação de plantio e a outra metade da dose em adubação de cobertura, realizada 30 dias após o transplante.

Utilizou-se irrigação por aspersão, sempre que necessário para manter o solo sempre úmido e adequado para um melhor desenvolvimento da cultura.

A colheita foi iniciada em 15 de dezembro de 2005, quando os legumes estavam em estádio reprodutivo R6, tendo como referência a escala de Fehr e Caviness, adaptada por Costa \& Marchezan (1982). Com a ajuda de um facão, cortaram-se as plantas acima da superfície do solo e no laboratório retiraram-se os legumes e realizaram-se as avaliações.

As características avaliadas foram: número médio de sementes por legume; massa fresca de legumes por planta; massa fresca de 100 sementes; produção de grãos imaturos por planta; produtividade estimada de grãos imaturos em g pl${ }^{-1} \mathrm{e} \mathrm{kg} \mathrm{ha}^{-1}$ e número médio de legumes por planta.

${ }^{4}$ VOLPE, C. A. (Faculdade de Ciências Agrárias e Veterinárias, UNESP Câmpus de Jaboticabal) Comunicação pessoal, 2005. 
Os dados obtidos foram submetidos à análise de variância, e as médias, comparadas pelo teste de Tukey, a $5 \%$ de probabilidade.

$\mathrm{Na}$ Tabela 1, são apresentadas as médias das características avaliadas para os dois genótipos de sojahortaliça de ciclo precoce, em diferentes densidades. Em todas as características avaliadas, com exceção do número médio de legumes por planta, não foram detectadas interações significativas entre os genótipos e densidades.

Para o número de sementes por legume, não se observaram diferenças entre os genótipos avaliados. Porém, essa característica fora influenciada pela densidade, sendo que, a utilização de 10 e 7 , proporcionaram médias superiores $(1,98$ e 2,00 sementes por legume, respectivamente) às encontradas na densidade 20 plantas por metro (1,62 semente por legume). Os valores obtidos no presente trabalho estão próximos dos observados por Castoldi et al. (2006a), que verificaram para os genótipos CNPSOI e JLM010, cultivados com 0,10 m entre plantas, 2,16 e 2,06 sementes por legume, respectivamente. Verificase que o plantio de soja-hortaliça menos adensado proporcionou maior número de sementes por legume, o que é altamente desejável.

Para a massa fresca de legumes por planta, não se verificaram diferenças significativas entre os genótipos. Mas essa característica foi influenciada, significativamente, pela densidade. Pode-se observar na Tabela 1 que, quanto maior a densidade, maior a produção de legumes por planta. Isso está relacionado ao fato de que, quando as plantas são submetidas a menores densidades, elas se desenvolvem mais e, conseqüentemente, acabam tendo produções por planta, maiores.

Quanto à massa fresca de 100 sementes, observouse que a cultivar JLM010 apresentou médias superiores à cultivar CNPSOI (85,25 e 57,75 respectivamente). Isso significa que os grãos imaturos do genótipo JLM010 são maiores quando comparados aos do genótipo CNPSOI, o que é muito desejável em cultivares de soja-hortaliça. Assim, o genótipo JLM010 apresenta grande potencial para a produção de soja-hortaliça, como já relatado por Castoldi et al. (2006a).

Com relação às densidades, não se verificaram diferenças entre 10 e 7 plantas por metro para a massa fresca de 100 sementes, sendo as médias delas superiores às encontradas na densidade de 20 plantas por metro. Portanto, essa característica é um fator muito importante na produção de soja-hortaliça, pois o menor número de plantas por área proporciona grãos maiores.
Esses resultados discordam dos observados por Castoldi et al. (2006b), que, ao avaliarem o efeito da densidade em genótipos de soja-hortaliça de ciclo tardio, verificaram que a massa fresca de 100 sementes não fora influenciada por essa característica. Isso pode ser explicado pelo fato de se tratarem de genótipos de ciclos diferentes e, portanto, terem comportamentos diferentes.

Para a produção de grãos imaturos por planta (PGIP) e para a produtividade estimada de grãos imaturos $\left(\mathrm{kg} \mathrm{ha}^{-1}\right)$, não se verificaram diferenças significativas, entre os genótipos avaliados. Vale ressaltar que, embora não tenham ocorrido diferenças para as características produção de grãos imaturos por planta e de produtividade estimada de grãos imaturos entre os genótipos avaliados, o genótipo JLM010 merece destaque especial por apresentar grãos maiores que o genótipo CNPSOI, o que é muito importante em cultivares de soja-hortaliça.

Com relação às densidades, observaram-se diferenças somente para a produção de grãos imaturos por planta (PGIP), que apresentaram as maiores médias de produção na densidade de 7 plantas por metro. Não foram detectadas diferenças entre genótipos para a produtividade estimada por hectare, não sendo afetada pelas densidades testadas. Esses resultados concordam com os observados por Castoldi et al. (2006b), que verificaram maiores produções por planta, na densidade de 7 plantas por metro, porém não observaram diferenças significativas entre as densidades para a produtividade.

As produtividades observadas no presente trabalho (7.951,16 kg ha-1 para o genótipo JLM010 e 8.917,15 $\mathrm{kg} \mathrm{ha}^{-1}$ para o genótipo CNPSOI) estão próximas das verificadas por Castoldi et al. (2006a), que relatam produtividades de $8.472,50 \mathrm{~kg} \mathrm{ha}^{-1}$ para o genótipo JLM010 e $9.637,50 \mathrm{~kg} \mathrm{ha}^{-1}$ para o genótipo CNPSOI, cultivados na densidade de 10 plantas por metro.

Observa-se que as cultivares de soja-hortaliça, quando cultivadas em densidades menores se desenvolvem mais, produzindo maior número de grãos por legume e esses, por sua vez, são maiores, refletindo numa produção por área. Vale a pena ressaltar que o plantio nessa situação tem outras vantagens, como o menor consumo de sementes e maior eficiência no controle de pragas e doenças.

Observou-se interação entre os genótipos avaliados e as densidades testadas apenas para o número médio de legumes por planta. De acordo com a Tabela 2, verifica-se que as maiores médias do número de legumes por planta 
Tabela 1 - Médias de seis características agronômicas em dois genótipos de soja-hortaliça de ciclo precoce.UNESPFCAV, Jaboticabal-SP, 2006.

\begin{tabular}{ccccccc}
\hline Cultivares & NSL & MFL/P $(\mathrm{g})$ & $\mathrm{MF}_{100}(\mathrm{~g})$ & $\mathrm{PGIP}\left(\mathrm{g} \mathrm{pl}^{-1}\right)$ & $\mathrm{PE}\left(\mathrm{kg} \mathrm{ha}^{-1}\right)$ & $\mathrm{NLP}$ \\
\cline { 2 - 7 } JLM010 & $1,88 \mathrm{a}$ & $71,33 \mathrm{a}$ & $85,25 \mathrm{a}$ & $48,71 \mathrm{a}$ & $7951,16 \mathrm{a}$ & $28,78 \mathrm{~b}$ \\
CNPSOI & $1,85 \mathrm{a}$ & $70,16 \mathrm{a}$ & $57,75 \mathrm{~b}$ & $52,51 \mathrm{a}$ & $8917,95 \mathrm{a}$ & $47,31 \mathrm{a}$ \\
\hline Teste F & $0,13^{\mathrm{NS}}$ & $0,17^{\mathrm{NS}}$ & $423,54 * *$ & $2,04^{\mathrm{NS}}$ & $3,44^{\mathrm{NS}}$ & $143,48^{* *}$ \\
DMS (Tukey, 5\%) & 0,22 & 8,97 & 4,25 & 8,46 & 1658,67 & 4,92 \\
\hline Densidades (D) & & & & & & \\
20 & $1,62 \mathrm{~b}$ & $39,50 \mathrm{c}$ & $64,05 \mathrm{~b}$ & $25,46 \mathrm{c}$ & $8487,83 \mathrm{a}$ & $23,35 \mathrm{c}$ \\
10 & $1,98 \mathrm{a}$ & $66,50 \mathrm{~b}$ & $74,01 \mathrm{a}$ & $49,91 \mathrm{~b}$ & $8318,47 \mathrm{a}$ & $36,05 \mathrm{~b}$ \\
7 & $2,00 \mathrm{a}$ & $106,25 \mathrm{a}$ & $76,46 \mathrm{a}$ & $76,47 \mathrm{a}$ & $8497,36 \mathrm{a}$ & $52,75 \mathrm{a}$ \\
\hline Teste F & $38,43^{* *}$ & $159,64^{* *}$ & $24,16^{* *}$ & $441,11^{* *}$ & $0,13^{\mathrm{NS}}$ & $135,63^{* *}$ \\
DMS (Tukey, 5\%) & 0,12 & 10,01 & 5,04 & 0,57 & 1048,47 & 4,47 \\
\hline Teste F (C x D) & $2,51^{\mathrm{NS}}$ & $0,92^{\mathrm{NS}}$ & $3,82^{\mathrm{NS}}$ & $1,41^{\mathrm{NS}}$ & $3,32^{\mathrm{NS}}$ & $6,73^{*}$ \\
CV (\%) parcelas & 9,15 & 9,76 & 4,58 & 12,88 & 15,14 & 9,96 \\
CV (\%) subparcelas & 5,19 & 10,62 & 5,29 & 6,79 & 9,33 & 8,81 \\
\hline
\end{tabular}

$\mathrm{NSL}=$ Número Médio de Sementes por Legume; MFL/P = Massa Fresca de Legumes por Planta; $\mathrm{MF}_{100}=$ Massa fresca de 100 Sementes; PGIP= Produção de grãos imaturos por planta; $\mathrm{PE}=$ Produtividade Estimada de Grãos Imaturos $\left(\mathrm{kg} \mathrm{ha}^{-1}\right) ; \mathrm{NVP}=$ Número Médio de Legumes por Planta.

Médias seguidas pela mesma letra na coluna não diferem entre si, pelo Teste de Tukey, a 5\% de probabilidade.

Tabela 2 - Resultados médios do número de legumes por planta obtidos no ensaio de genótipos de soja-hortaliça de ciclo precoce, em três densidades de plantas. UNESP-FCAV, Jaboticabal-SP, 2006.

\begin{tabular}{ccccr}
\hline & \multicolumn{4}{c}{ Densidade de plantas } \\
\cline { 2 - 4 } Cultivares & 20 & 10 & 7 & Teste F \\
\hline JLM010 & $18,97 \mathrm{Cb}$ & $27,12 \mathrm{Bb}$ & $40,25 \mathrm{Ab}$ & $40,98^{* *}$ \\
CNPSOI & $31,72 \mathrm{Ca}$ & $44,97 \mathrm{Ba}$ & $65,25 \mathrm{Aa}$ & $101,39^{* *}$ \\
\hline Teste F & $26,46^{* *}$ & $51,87^{* *}$ & $101,74^{* *}$ & \\
\hline
\end{tabular}

Médias seguidas por letras maiúsculas nas linhas e minúsculas nas colunas não diferem entre si, pelo Teste de Tukey, a 5\% de probabilidade.

foram encontradas na densidade de 7 plantas por metro. Observou-se também que, independentemente da densidade, a cultivar CNPSOI foi a que apresentou o maior número médio de legumes por planta.

Embora o genótipo CNPSOI tenha apresentado maior número de legumes por planta, e valores de número de sementes por legume, massa fresca de legumes por planta, produção de grãos imaturos por planta e produtividade estimada de grãos imaturos por hectare semelhantes ao do genótipo JLM010; este não é recomendado, devido a seus grãos serem pequenos, o que os torna menos interessantes ao consumidor.

Com base nos resultados obtidos, o genótipo JLM010 é o mais recomendado para a região de Jaboticabal-
SP e deve ser plantado na densidade de 7 plantas por metro.

\section{REFERÊNCIAS BIBLIOGRÁFICAS}

CASTOLDI, R.; BRAZ, L. T.; CHARLO, H. C. O.; CARRÃOPANIZZI, M. C.; MENDONÇA, J. L. Desempenho de genótipos de soja-hortaliça, em Jaboticabal-SP. Horticultura Brasileira, Brasília, v. 24, n. 1, jul. 2006a. Suplemento 2. CD-ROM.

CASTOLDI, R.; BRAZ, L. T.; CHARLO, H. C. O.; VARGAS, P. F.; CARRÃO-PANIZZI, M. C.; MENDONÇA, J. L. Influência do espaçamento entre plantas em características agronômicas de dois genótipos de ciclo tardio de sojahortaliça, em Jaboticabal-SP. Horticultura Brasileira, Brasília, v. 24, n. 1, jul. 2006b. Suplemento 2. CD-ROM. 
COSTA, J. A.; MARCHEZAN, E. Características dos estádios de desenvolvimento da soja. Campinas: Fundação Cargill, $1982.30 \mathrm{p}$.

EMPRESA BRASILEIRA DE PESQUISA AGROPECUÁRIA. Centro Nacional de Pesquisa de Solos. Sistema brasileiro de classificação de solos: produção de informação. Rio de Janeiro, 1999. 412 p.

EMPRESA BRASILEIRA DE PESQUISA AGROPECUÁRIA. Tecnologia de produção de soja: região central do Brasil 2004. Londrina, 2003. 237 p. (Sistemas de produção, 4).
KONOVSKY, J.; LUMPKIN, T. A. Edamane production and use: a global perspective. In: INTERNATIONAL CONFERENCE SOYBEAN PROCESSING AND UTILIZATION, 1990, Gongzhuling. Program and abstracts... Gongzhuling: Jilin Academy of Agricultural Science, 1990.

MENDONÇA, J. L.; CARRÃO-PANIZZI, M. C. Soja-verde: uma nova opção de consumo. Brasília, DF: Embrapa Hortaliças, 2003. 8 p. (Comunicado técnico).

RAIJ, B. V.; CANTARELLA, H.; QUAGGIO, J. A.; FURLANI, A. M. C. (Eds.). Recomendações da adubação e calagem para o Estado de São Paulo. 2. ed. Campinas: IAC, 1996. 285 p. (Boletim técnico, 100). 